\title{
THE MEDIATING ROLE OF SUPPLIER NETWORK, THE MODERATING ROLE OF FLEXIBLE RESOURCES IN THE RELATIONSHIP BETWEEN LEAN MANUFACTURING PRACTICES AND THE ORGANIZATIONAL PERFORMANCE
}

\author{
Sakapas Saengchai ${ }^{1}$, Kittisak Jermsittiparsert ${ }^{2}$ \\ ${ }^{1}$ Faculty of Humanities and Social Science, Suan Sunandha Rajabhat University, Bangkok, Thailand, ${ }^{2}$ Department for \\ Management of Science and Technology Development, Ton Duc Thang University, Ho Chi Minh City, Vietnam; Faculty \\ of Social Sciences and Humanities, Ton Duc Thang University, Ho Chi Minh City, Vietnam \\ E-mail: sakapas.sa@ssru.ac.th, kittisak.jermsittiparsert@tdtu.edu.vn
} Article History: Received on $25^{\text {th }}$ February 2019, Revised on $28^{\text {th }}$ April 2019, Published on $25^{\text {th }}$ August 2019

\begin{abstract}
Purpose: Given the internationalization of business today, it illustrates the importance of companies looking for overseas market opportunities for the capture of and sustainability of competitive advantage. Following the success of companies from newly developed nations such as the Far East Asian nations of the Republic of Korea and the Republic of China, Taiwan and South East Asian countries such as Singapore, emerging economies are shifting to external sector growth through export industries from the internal sector growth of import substitutes industries. Thus the current study is interested in exploring the nexus between supply chain integration, export marketing strategies and export performance of Indonesian manufacturing firms.
\end{abstract}

Methodology: Employing the survey-based methodology, the SEM-PLS technique is used to test the hypothesized relationships. So, the current study has used SEM-PLS as a statistical tool to answer the research questions raised in this study and research objectives envisaged in the current study.

Results: The findings of the study have provided support to the theoretical foundation and proposed hypothesis of the current study. Current study will be helpful for policymakers and practitioners in understanding the issues related to supply chain risk, supply chain integration and supply chain agility. In the author's knowledge this is among very few pioneering studies on this issue.

Keywords: supplier network, flexible resources, lean manufacturing practices, organizational performance.

\section{INTRODUCTION}

Manufacturing industries have extensive involvement, especially in the manufacture and processing of goods and enjoy either the creation of a new commodity or as an additional value. The manufacturing industry accounted for most of the industrial sector in the developed countries. In the manufacturing industry the resulting end product can be either ready to be sold directly to customers or as intermediate goods or work in the processes used in the production process (Chen et al., 2016; Sen et al., 2017; Sandy, 2018). In a mixed market economy, manufacturing occurs under some regulatory agency of a government. Through history, the earliest in manufacturing is usually done by a single skilled artisan with assistants with their apprenticeship training. Before the Industrial Revolution, most of the production occurs in rural areas where the creation of home-based service as a strategy in addition to subsistence agriculture and continues to do so in places. Entrepreneurs also recommends the creation of some households to become a single company through the putting-out system. Manufacturing been a major challenge in the making for more than 10 years ago that are not necessarily educated or skilled labor shortages, although it is an issue, compared to searching for people who have good work ethics or discipline (Aksoy, 2017; Sharif et al., 2017; Setiyawati et al., 2018).

Because of this problem often occurs in the manufacturing industry, companies must think of something to overcome this problem. Various theories introduced to overcome this problem. Multi-step renewal enhancer made to improve the company's performance compared with other competitors. Through problems that plagued the problem of workers who are not disciplined and often stop working very negative impact on the company's performance, particularly its financial performance.

Stoian et al. (2011) states that the study of empirical research falls short in consistency that confirm this relationship that relates to the set extends operation known as the practice of lean manufacturing and is considered as a set of synergistic management practices of modern manufacturing integrated that are normally classified under a subset of the total maintenance like productive maintenance (TPM), total quality management (TQM), just- in-time (JIT), and management of human resource that supports the practice of including employee empowerment and teamwork. Lean Manufacturing include statistical process control (SPC), the rationalization of the supply base, customer integration requirements, in-house designed technology, setup engineering, integrated product design, team employee, pull production, employee participation in problem solving, information providers sharing and partnership, and cellular manufacturing.

The several of organizations have been using lean manufacturing to compete global basis, and it is considered as an evolution in the process of continuous improvement in manufacturing concept (Ruzo et al., 2011). The way products are 
manufactured has included mass production, craft, and lean manufacturing. Craft led to the mass production and mass production led to lean manufacturing that has revolutionized the way products are manufactured in modern times. Lean manufacturing commonly known as the Toyota Production System (TPS) emerges out of necessity as a means for Japanese automobile manufacturers to compete, beginning with the Toyota Motor Company.

Sousa and Lengler (2009) invented the mass production that changed the way products are made in many industries and is very important in promoting the concept that led to the creation of world led to world dominance in automobile manufacturing for domestic automobile manufacturers. In 1955, big three automobile manufacturing accounted for 95 percent of all sales for Ford, GM, and Chrysler (Helleiner and Kirshner, 2014). Both Helleiner and Kirshner (2014) and Azar and Ciabuschi (2017) were renaissances in their day, in the improvement of manufacturing methods.

In comparison to lean manufacturing, mass production is more to human effort, more to manufacturing space, more to investment in tools, and more to development time. It results in more defects, higher costs, less quality, and longer response time, that leads to reduced organizational performance. The lean manufacturing system is a method of manufacturing products just in time. The concept of lean manufacturing principles employs simple means for communicating material requirements, and a manual method called Kanban provides a signal for replenishment of materials required by the operator (Basheer et al., 2019). This is made possible with instructions on a card enclosed in a plastic envelope on teamwork between employees, and the Kanban for material replenishment and problem-solving approaches, lean manufacturing has propelled the Japanese automobile manufacturers to a competitive advantage

\section{LITERATURE REVIEW}

\section{Lean Manufacturing Practices}

In attempting to relate lean manufacturing and its potential benefits after its implementation, it is important to differentiate between practices and performance. Following (Navarro and Boveris, 2009) this study defined practices as a combination of activities or approaches done to achieve a set of goals (e.g., certain type of performance). While, performance was defined as a set of achievement gained after implementing a set of practices. Hence, borrowing terminology of system theory, practices are inputs, whereas performance is output resulted from processing a set of practices. Thus, the ultimate result expected from manufacturing practices implementation is performance.

In lean the essence of the strategy is basically to have a company-wide integrated effort to achieve process improvement and waste reduction (Filipe and Montgomery, 2005). Lean practices refer to the practices common to the organizations implementing lean manufacturing. For example in the case of the semiconductor industry in Malaysia. Navarro and Boveris (2009); Filipe and Montgomery (2005) discussed on the reasons why firms in general were reluctant to emphasize supply chain partnering in order to improve their supply chain despite knowing its importance for performance (such as cost inventory reduction through lean practices). The firms gave reasons such as the lack of human resources. issues of confidentiality (which hinders flow of information Even though the findings would be limited in its generalization due to it being only a comparison between two companies it does shed some light as to the scenario in the world at large and in Malaysia in particular. This is reinforced by others who felt that in the midst of numerous failures in implementing practices to improve the supply chain the question remains whether any practices (such as lean practices) could positively impact the supply chain performance (Sousa et al., 2008).

By working on this identified constraint, the performance (internal supply chain) of the organization would be improved. The theory encourages managers to identify what is preventing them from moving towards their goals and to find the relevant solutions moving forward. Lean practices implementation was found to the effective in improving the information flow (He et al., 2013); (Hafeez et al., 2018) which in turn is key to increasing productivity and ultimately the internal supply chain. Apart from this it also has a strong influence on the integration of both information and physical flow along the supply chain (Filipe and Montgomery, 2005). This would result in cost efficiency as waste are eliminated or reduced through lowering of inventory and focus improving the quality of products in the supply chain (He et al., 2013). This thought is reinforced by Gkypali et al. (2015). Who stressed the importance of lead time (Turn-around-Time) reduction in a lean implementation? They argue that in the implementation the supply chain works well where demand is relatively stable and predictable with low variety of products type. This argument however is to a certain extent disqualified (Durmuşoğlu et al., 2012) when they highlighted some attributes that are relevant in a lean implementation. These are a) ability to better manage capability through obtaining the demand data efficiently such as through effective use of information communication technology (ICT)

This concurs with the view by Navarro and Boveris (2009). Who puts forth his opinion of the importance of effectively and efficiently processing the necessary information required? $\mathrm{b}$ ) waste and cost reduction through policy procedures and practices that eliminates waste. c) Determining the best way to manage a process and then standardizing it across the chain. d) cultural change in getting the lean concepts accepted in the organization and e) ability to garner the members in the supply chain towards maximizing the value stream. Though technology has made many fast communication channels available to the masses the aim is not about only being fast but rather being effective and efficient. Towards this end, lean practices provides a great potential as was shown in a research (a printed circuit board electronics manufacturer located in United States of America) which highlighted improved information flow through the implementation (Morgan et al., 
2012). Pertaining to this similar field. in a Malaysian context, a group of researchers did a study and made the same findings in an aerospace manufacturing company Lean practices by itself have come a long way (being made prominent particularly In the automobile industry). After the publication of Sousa et al. (2008) and the other seminal works describing TPS. Many other notable articles associated with TPS were produced. There are indeed many success stories of how employing lean practice brings about positive results.

This trend shows increase in the number of organizations and industries embracing lean practices (Morgan et al., 2012); (Durmuşoğlu et al., 2012). It is spurred on by studies that shows lean practices not only display superior performance. but also, that these practices were not culturally bound to one country and thus indeed transferable to other countries and organizations. Examples of successful implementation of lean practices can be seen in countries such as in Japan, India, China, United States, and United Kingdom as well as in Southeast Asia (Fernández-Mesa and Alegre, 2015). Prominent examples can be seen in Toyota not only in Japan but elsewhere as stated earlier. Among the issues that are commonly faced by organizations which prompt them to consider implementing lean practices are such as decision making, key performance indicators, inventory control, communicating to the shop floor the top management strategy, managing of change and leadership. The root of lean practices (lean manufacturing) started from the automobile industries and its success lies in having a workforce that is committed. The practice became famous through the work of Basheer et al. (2019) in the book "The Machine that Changed the World" and since then the philosophy of lean has spread into diverse industries. To name a few it has being utilized in the printing industry, agriculture medical device, aerospace, meat processing, textile, food and chemical etc. Lean practices have also penetrated into the electronic industries of which some studies were carried out also in Malaysia.

\section{Flexible Resources}

For an organization to perform it would need to understand the customer's needs and respond to it. Customer's request comes in various forms such as quality, pricing, turn-around-time etc. In fact customers today are demanding more variety, better quality and service including reliability and faster delivery. With new technological developments occurring at a faster pace, new product innovations and improvements in manufacturing processes can be expected to occur more frequently. In order for the organization to be on the cutting edge in term of supply chain flexibility, it need to be intimate with the customer so as to know their needs such as their specific specifications, market behaviour, product demand trend (such as whether it is seasonal or not), life span of product etc. This better connectivity with the customers will be useful inputs even for the internal supply chain as the members working there will know what adds value to customers and what doesn't (Fernández-Mesa and Alegre, 2015). By being so sensitive to the customer's need the organization can thus make appropriate decisions that are value added. Despite the need for supply chain flexibility the overzealous effort of some organizations to create agility in response to the ever-uncertain environment and severe customer request (both for quality and quantity) it often leads to complexity which often time is counter-productive (Tan and Sousa, 2015).

The use of multi-skilled workers and multi-functional machines and equipment should be supported by training to perform multiple tasks. It seems that multi-skilled workers, multifunctional machines, and training are critical factors in a lean manufacturing system (Fernández-Mesa and Alegre, 2015). Human resources take important roles at all aspects of an organization. One of the fundamental aspects for the success of an organization is the power of its workers. In the context of lean manufacturing, Tan and Sousa (2015) stated that the roles played by workers differentiate between lean and nonlean systems. In a lean system, workers must be able to perform multiple tasks, which is less important in a non-lean system. So, workers can be involved in a broad number of manufacturing activities.

(Julian, 2018) characterized workers' involvement as a critical factor for the success of lean manufacturing. Optimum deployment of resources can be accomplished through flexible workers. Thus, to enhance workers' flexibility, they must undergo several trainings in order to be able to perform multiple jobs and possess redundant capabilities. Descotes and Walliser (2018) stated that the better results of lean manufacturing implementation depend on having well-trained workers. In similar opinion, Martin et al. (2017) stated that lean plants were characterized by greater use of training. Thus, companies that implement most of the lean practices are those that take care to train workers in employing the practices. Literature had different expressions for the training, such as cross-functional training (Lee and Griffith, 2004) multifunctional training and multiple task trainings. However, the basic idea is to keep multiple abilities of workers and to maintain their high-skill level. Previous studies had different terms to express multiple abilities of employees, such as cross-functional workforce, and multi-functional workers. Although they expressed differently, it implied that development of multi-skilled workers has established in several studies. By employing multi-skilled workers, the contents of individual tasks could be enriched. They can engage on several different jobs. Ultimately, wastes caused by under-utilization of human resources are eliminated.

\section{Supplier Networks}

Lean manufacturing activities are not only related to internal properties of a production system, but also to entire supply chain networks, within and across companies. Externally, extensive literature review indicates supplier networks (or often called as JIT partnership and JIT purchasing) as a critical factor for lean manufacturing success. Close relationships with suppliers are indispensable for the triumph of lean manufacturing. Nowadays, practitioners give much attention to the role of suppliers to support a company to enhance its performance (Julian and O'Cass, 2004). 
One of the most important requirements of the lean manufacturing system is on-time delivery. Suppliers must be able to deliver the products as promised, just as it is needed, in the right quantity at the right time to the right place. To enhance suppliers' ability to fulfil this requirement, the buyer must design a transportation system compatible with JIT delivery. According to Navarro et al. (2010) the buyer must design delivery times, types of carriers, routing decisions, and shipping processes. These facilitate the suppliers to deliver their products as promised (on-time delivery) and faster (fast delivery). Ultimately, the buyer could depend upon on-time delivery from suppliers. Nowadays, due to the importance of JIT delivery by suppliers, it is considered as a key activity of lean manufacturing (Descotes and Walliser, 2018). Lean manufacturing system requires suppliers' involvement in a production system. Erem and Menguc (2015) noted that it could contribute substantially to process enhancement and variance reduction. The involvement is very important to encourage suppliers to develop their capabilities in terms of product quality, product design, product development (Descotes and Walliser, 2018) and continuous improvement (Ruskowski and Pauwels, 2016).

To ensure their involvement, supplier development programs should be regularly conducted by lean manufacturers. Cui et al. (2014) stated that lack of training for suppliers was a major obstacle to the employment of lean manufacturing. Hence, through supplier development programs, suppliers can be more involved in many parts of focal company's activities.

Another characteristic of supplier networks is long-term relationship with suppliers). Several researchers proposed different expression for this practice, such as the long-term contract, long-term arrangements with suppliers, long-term commitment with suppliers and long-term agreement with suppliers. Lean manufacturing requires a steady production system. Therefore, manufacturer (or buyer) needs to select reliable suppliers to ensure superior quality of product as well as to keep lower costs. Several scholars, such as (Lengler et al., 2013) suggested to maintain long-term relationship with a small number of suppliers that have been proven credible, certified for quality, and high performance. In line with this suggestion, Navarro-García et al. (2014) recommended that manufacturer (buyer) should consider whether the suppliers are certified for quality or not. In other words, suppliers should be selected based on quality standards. Through this activity, buyer can ensure high quality of product without performing any inspection. This could be realized because suppliers can assure that quality specifications have been met before the products are delivered. Other than that, long-term relationship with a smaller number of suppliers can result in a better channel of communication, require less paperwork, and operate at lower coordination costs.

\section{Lean manufacturing and Organizational performance}

Lengler et al. (2013) A review the literature revealed a number of methodological issues that may lead to different findings as follows; 1 . The use of indicators that are not relevant to lean manufacturing. As lean manufacturing is aimed to eliminate waste in a production system, all the practices should be relevant to this aim. Irrelevant lean manufacturing indicator such as value stream mapping (VSM) was observed in the study of Navarro-García et al. (2014) since the VSM is not a method used to eliminate waste but the method to identify waste. The researchers also classified takt time as a tool of JIT. This classification is inappropriate. Takt time was widely defined as the interval at which a product is moved ahead to the next workstation, which is calculated by dividing the available production time per day with production volume per day. At a final process, it reflects the rate at which a finished product is completed. Thus, it is used as an input of synchronizing production rate and demand rate. Furthermore, shorter takt time can be an output of lean manufacturing implementation. Hence, even though (Singh and Mahmood, 2014) found a strong relationship between JIT tools and operations performance, the presence of takt time is not operationally appropriate. Inappropriate indicator was also observed in He et al. (2013). The researchers included electronic data interchange (EDI) as one indicator of lean manufacturing. The study found that EDI had no significant relationship with operations performance and financial growth. In line with this finding, in-depth literature review indicated that emphasizing EDI as a practice of lean manufacturing did not frequently appear in literature. However, instead of using a general term like EDI, the term like ekanban (electronic kanban) may be more appropriate. In addition, and exploratory factor analysis grouped kanban as one of the supplier strategy factors, while there was a consensus among researchers and practitioners emphasizing kanban as a practice implemented not only in the relationship with suppliers, but also in the production process. Hence, it seems that the result of exploratory factor analysis in this study was not practically rationalized. The improper grouping of the practices may raise problematic results.

Even if the methods or tools are relevant to lean manufacturing, it is not proper to measure the level of its implementation based on a limited number of practices. Durmuşoğlu et al. (2012) noted, although its synergistic effects on companies' performance are widely believed, most of the empirical studies focused on the relationship between individual practices and performance rather than considering improvement resulted from implementation of a set of lean manufacturing practices. The use of limited indicators to assess lean manufacturing and performance in a plant may not capture its actual condition. This was found in a number of studies. For example, Fernández-Mesa and Alegre (2015) who assessed lean manufacturing practices only in terms of quality improvement, setup time reduction, and cellular manufacturing.

Even though the study concluded a significant relationship between lean manufacturing, non-financial and financial performance measures, the practices did not represent the lean manufacturing as a whole. 


\section{METHODOLOGY}

In the quantitative phase, the Structural Equation Modelling (SEM) approach was used to analyze the data. The SEM is recognized as a second-generation technique, which allows the simultaneous modelling of relationship among multiple variables (Descotes and Walliser, 2018; Singh, 2018; Supian and Ab, 2018; Suy et al., 2018). In the first-generation technique (i.e., regression model), according to Lee and Griffith (2004) two separated steps of analysis are required. In the first step, factor analysis is conducted to examine how measures load on the constructs. Separately, in the second step, the measures with acceptable factor loading are examined to assess hypotheses. Hypotheses' testing is performed individually based on the number of hypotheses. Unlike the regression technique, SEM combines measurement and structural model in the same analysis. A measurement model provides the link between observed variables (manifest variables) and the underlying unobserved variable (latent variable) they are designed to measure. In other words, a measurement model relates a latent variable to indicators. In contrast, a structural model defines the 139 relations among latent variables. Thus, the SEM enables the author to assess the set of factor analyses and multiple regressions simultaneously.

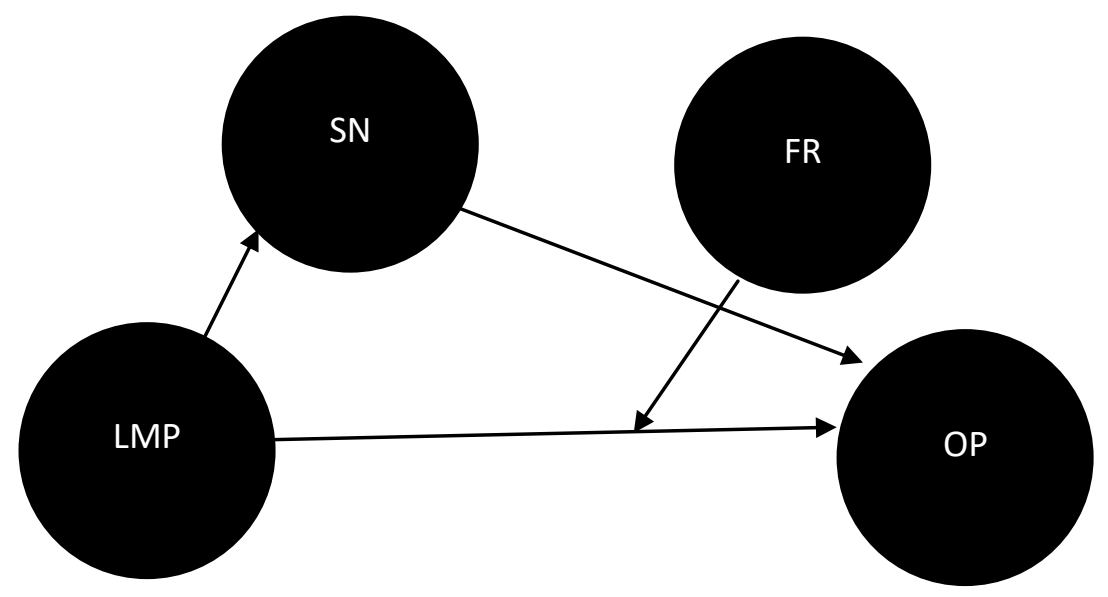

Figure 1: Conceptual Framework

\section{RESULTS}

Regression explain how much of the variation in the dependent variable of export performance was caused by the independent variables of export marketing adaptation strategies. In other words, it established the predictive ability of different export marketing adaptation strategies as the set of independent variables, on export performance which is the dependent variable. This was performed by including all the independent variables into the analysis through a simultaneous or standard multiple regression. The analysis indicated the statistical significance of the individual independent variables as well as the overall model.

In performing multiple regressions, a correlation matrix was produced not only showing the relationship between the outcome variable and the predictor variables but also the relationship among the independent variables. High correlation among these independent variables would result in the problem of multicollinearity and thus adverse effect of the stability of the parameter estimates. To assess multicollinearity, the bivariate correlation between two independent variables indicated in the correlation matrix was checked. If among the independent variable's correlation coefficient is 0.70 or more, omission of one variable would be considered to solve the problem of multicollinearity. As part of the multiple regression analysis in SPSS, collinearity statistics in the form of variance inflation factors (VIF) were computed to evaluate multicollinearity. The presence of multicollinearity would be indicated by a VIF score of above 10. In other words, if the VIF score was below 10, there would be no violation of the multicollinearity assumption.

Cronbach alpha values have been estimated for checking the reliability of variables. In order to validate that all the measured items have high factor loadings and reliability, validity test was performed. The ability of an item to estimate what it should estimate is referred as validity.

Table 1: Reliability

\begin{tabular}{c|c|c|c}
\hline & CR & AVE & Cronbach Alpha \\
\hline EPDAS & 0.925 & 0.872 & 0.985 \\
\hline IEPRCAS & 0.702 & 0.777 & 0.924 \\
\hline EDAS & 0.920 & 0.821 & 0.873 \\
\hline EPROAS & 0.812 & 0.832 & 0.926 \\
\hline SCI & 0.861 & 0.831 & 0.923 \\
\hline EP & 0.831 & 0.842 & 0.919
\end{tabular}


Factor analysis involves the reduction of data for summarising the structure of variable. The other two categories of factor analysis are explanatory and confirmatory factor analysis. The correlation structure against the set structure is analyzed in the confirmatory factor analysis. It is estimated whether the criterion of goodness of fit is satisfied or not. The correlation structure of the data is assessed in exploratory factor analysis. It is also regarded as reduction process for the data. The variables supportive in the estimation of factors included in the model are also identified. It is observed in confirmatory factor analysis whether there exists any correlation among the observed variables and the factors are reliable. Moreover, the estimation of every factor is supported by the observed variables. For internal reliability and discovering the structuring factors, EFA can be used. However, the method is not good for theory testing. The association among the variables can be simplified and described through this analysis. For theory testing, CFA approach is considered effective.

When the p-value for Bartlett Sphericity is less than 0.05 , it reflects that the factor analysis is effective. The value needs to be above 0.6 for KaiserMeyer-Olkin case. When the value is above 0.6 , it reflects there is a need to add more variables in the model or collect more data. The sampling adequacy measure should be greater than 0.50 . It is suggested to eliminate the variables having item loadings lesser than 0.05 . In measuring the reliability of an item, it is estimated whether there is any error or bias. It is ensured through reliability test that the estimating items are stable at a given time. The value lies within 0-1. Higher internal consistency is indicated through the high value of Cronbach alpha. Therefore, the internal consistency among the variables is determined through Cronbach alpha. The low range value of reliability test came 0.717 and high range as 0.917. To observe the value of consistency, a rule of thumb is used. According to rule of thumb, the acceptable value is considered to be 0.50 or above. When the value is below 0.05 , it is not accepted. The desired range of value for reliability is $0.5-0.6$. The significance of the path coefficients was assessed using the standard bootstrapping procedure, which included 5000 bootstrap samples and 266 cases as recommended.

Table 2: Direct Effect

\begin{tabular}{c|c|c|c|c}
\hline & ( $)$ & SD & $\begin{array}{c}\text { T- } \\
\text { value }\end{array}$ & P-Values \\
\hline H1 & 0.211 & 0.135 & 3.211 & 0.000 \\
\hline H2 & 0.357 & 0.152 & 3.678 & 0.000 \\
\hline H3 & 0.321 & 0.178 & 3.321 & 0.000 \\
\hline H4 & 0.342 & 0.165 & 3.234 & 0.000 \\
\hline H5 & 0.451 & 0.221 & 3.345 & 0.000 \\
\hline
\end{tabular}

The moderation effect is shown in table 3

Table 3: Indirect Effect

\begin{tabular}{l|l|l|l|l}
\hline & $(\boldsymbol{\beta})$ & SD & T-value & P-Values \\
\hline H6 & 0.211 & 0.135 & 3.211 & 0.000 \\
\hline H7 & 0.357 & 0.152 & 3.678 & 0.000 \\
\hline H8 & 0.453 & 0.187 & 3.768 & 0.000 \\
\hline H9 & 0.408 & 0.132 & 3.968 & 0.000 \\
\hline
\end{tabular}

\section{CONCLUSION}

Export Marketing Strategy and Export Performance In a seminal work on export performance, investigate the relationship between marketing strategy and export performance. Information is gathered via personal interviews with management personnel involved in export marketing. A pilot study with export marketing managers is conducted to validate the content of the questionnaire, where variables and scales considered irrelevant are taken out in the final instrument. The sampling frame consisted of export companies compiled from both the government export development agencies and from various business associations related to trade given the internationalization of business today, it illustrates the importance of companies looking for overseas market opportunities for the capture of and sustainability of competitive advantage. Following the success of companies from newly developed nations such as the Far East Asian nations of the Republic of Korea and the Republic of China, Taiwan and South East Asian countries such as Singapore, emerging economies are shifting to external sector growth through export industries from the internal sector growth of import substitutes industries. Thus the current study is interested in exploring the nexus between supply chain integration, export marketing strategies and export performance of Indonesian manufacturing firms. Employing the survey-based methodology, the SEM-PLS technique is used to test the hypothesized relationships. So, the current study has used SEM-PLS as a statistical tool to answer the research questions raised in this study and research objectives envisaged in the current study. The findings of the study have provided support to the theoretical foundation and proposed hypothesis of the current study. Current study will be helpful for policymakers and practitioners in understanding the issues related to supply chain risk, supply chain integration and supply chain agility. In the author's knowledge this is among very few pioneering studies on this issue. 


\section{REFERENCES}

1. Aksoy, H., 2017. How do innovation culture, marketing innovation and product innovation affect the market performance of small and medium-sized enterprises (SMEs). Technology in Society, 51: 133-141. https://doi.org/10.1016/j.techsoc.2017.08.005

2. Azar, G. and F. Ciabuschi, 2017. Organizational innovation, technological innovation, and export performance: The effects of innovation radicalness and extensiveness. International Business Review, 26(2): 324-336. https://doi.org/10.1016/j.ibusrev.2016.09.002

3. Basheer, M., M. Siam, A. Awn and S. Hassan, 2019. Exploring the role of TQM and supply chain practices for firm supply performance in the presence of information technology capabilities and supply chain technology adoption: A case of textile firms in Pakistan. Uncertain Supply Chain Management, 7(2): 275-288. https://doi.org/10.5267/j.uscm.2018.9.001

4. Chen, J., C.M. Sousa and X. He, 2016. The determinants of export performance: A review of the literature 20062014. International Marketing Review, 33(5): 626-670.https://doi.org/10.1108/IMR-10-2015-0212

5. Cui, A.P., M.F. Walsh and S. Zou, 2014. The importance of strategic fit between host-home country similarity and exploration exploitation strategies on small and medium-sized enterprises' performance: A contingency perspective. Journal of International Marketing, 22(4): 67-85.https://doi.org/10.1509/jim.14.0045

6. Descotes, R.M. and B. Walliser, 2018. International marketing related competences and SMEs' export performance during the recession. Projects/Proyectica/Projectique, 3: 61-82. https://doi.org/10.3917/proj.021.0061

7. Durmuşoğlu, S.S., G. Apfelthaler, D.Z. Nayir, R. Alvarez and T. Mughan, 2012. The effect of governmentdesigned export promotion service use on small and medium-sized enterprise goal achievement: A multidimensional view of export performance. Industrial Marketing Management, 41(4): 680-691. https://doi.org/10.1016/j.indmarman.2011.09.016

8. Erem, T. and B. Menguc, 2015. A reexamination of an operational model of export marketing strategyperformance relationship: An empirical study of Turkish export ventures. Proceedings of the 1998 Multicultural Marketing Conference. Springer, Cham. pp: 65-71.https://doi.org/10.1007/978-3-319-17383-2_10

9. Fernández-Mesa, A. and J. Alegre, 2015. Entrepreneurial orientation and export intensity: Examining the interplay of organizational learning and innovation. International Business Review, 24(1): 148-156. https://doi.org/10.1016/j.ibusrev.2014.07.004

10. Filipe, L.L. and D.B. Montgomery, 2005. The relationship between export assistance and performance improvement in Portuguese export ventures: An empirical test of the mediating role of pricing strategy adaptation. European Journal of Marketing, 39(7/8): 755-784.https://doi.org/10.1108/03090560510601752

11. Gkypali, A., A. Rafailidis and K. Tsekouras, 2015. Innovation and export performance: Do young and mature innovative firms differ? Eurasian Business Review, 5(2): 397-415.https://doi.org/10.1007/s40821-015-0030-4

12. Hafeez, M.H., M.F. Basheer, M. Rafique and S.H. Siddiqui, 2018. Exploring the links between TQM practices, Business innovativeness and firm performance: An emerging market perspective. Pakistan Journal of Social Sciences, 38(2): 485-500.

13. He, X., K.D. Brouthers and I. Filatotchev, 2013. Resource-based and institutional perspectives on export channel selection and export performance. Journal of Management, 39(1): 27-47. https://doi.org/10.1177/0149206312445926

14. Helleiner, E. and J. Kirshner, 2014. The Great Wall of money: Power and politics in China's international monetary relations. Cornell University Press.

15. Julian, C.C., 2018. The theoretical underpinnings of government policy, turbulence and performance in the service sector: A conceptual framework. Journal of Financial Services Marketing, 23(1): 1-11. https://doi.org/10.1057/s41264-018-0041-1

16. Julian, C.C. and A. O'Cass, 2004. The antecedents of export marketing performance: an Australian perspective. Journal of Asia Pacific Marketing, 3(2): 99.https://doi.org/10.1300/J098v05n01_02

17. Lee, C. and D.A. Griffith, 2004. The marketing strategy-performance relationship in an export-driven developing economy: A Korean illustration. International Marketing Review, 21(3): 321-334. https://doi.org/10.1108/02651330410539648

18. Lengler, J.F., C.M. Sousa and C. Marques, 2013. Exploring the linear and quadratic effects of customer and competitor orientation on export performance. International Marketing Review, 30(5): 440-468. https://doi.org/10.1108/IMR-03-2011-0087

19. Martin, S.L., R.G. Javalgi and E. Cavusgil, 2017. Marketing capabilities, positional advantage, and performance of born global firms: Contingent effect of ambidextrous innovation. International Business Review, 26(3): 527543.https://doi.org/10.1016/j.ibusrev.2016.11.006

20. Morgan, N.A., C.S. Katsikeas and D.W. Vorhies, 2012. Export marketing strategy implementation, export 
marketing capabilities, and export venture performance. Journal of the Academy of Marketing Science, 40(2):

271-289.https://doi.org/10.1007/s11747-011-0275-0

21. Navarro-García, A., J. Arenas-Gaitán and F.J. Rondán-Cataluña, 2014. External environment and the moderating role of export market orientation. Journal of Business Research, 67(5): 740-745. https://doi.org/10.1016/j.jbusres.2013.11.037

22. Navarro, A. and A. Boveris, 2009. Brain mitochondrial dysfunction and oxidative damage in Parkinson's disease. Journal of Bioenergetics and Biomembranes, 41(6): 517-521.https://doi.org/10.1007/s10863-009-9250-6

23. Navarro, A., F. Losada, E. Ruzo and J.A. Diez, 2010. Implications of perceived competitive advantages, adaptation of marketing tactics and export commitment on export performance. Journal of World Business, 45(1): 49-58.https://doi.org/10.1016/j.jwb.2009.04.004

24. Ruskowski, I. and P. Pauwels, 2016. A dynamic perspective on internet capabilities and export marketing performance.

25. Ruzo, E., F. Losada, A. Navarro and J.A. Díez, 2011. Resources and international marketing strategy in export firms: Implications for export performance. Management Research Review, 34(5): 496-518. https://doi.org/10.1108/01409171111128698

26. Sandy, W., 2018. Factors influencing indonesian students satisfaction during their studies in china. Asian Journal of Contemporary Education, 2(2): 136-148.https://doi.org/10.18488/journal.137.2018.22.136.148

27. Sen, D., S. Bingol and O. Vayvay, 2017. Strategic enterprise management for innovative companies: The last decade of the balanced scorecard. International Journal of Asian Social Science, 7(1): 97-109. https://doi.org/10.18488/journal.1/2017.7.1/1.1.97.109

28. Setiyawati, H., D. Iskandar and Y.S. Basar, 2018. The quality of financial reporting through increasing the competence of internal accountants and accrual basis. International Journal of Economics, Business and Management Studies, 5(1): 31-40.https://doi.org/10.20448/802.51.31.39

29. Sharif, I., S.R.A. Wahab and A. Sarip, 2017. Psychological contract breach and feelings of violation: Moderating role of age-related difference. International Journal of Asian Social Science, 7(1): 85-96. https://doi.org/10.18488/journal.1/2017.7.1/1.1.85.96

30. Singh, H. and R. Mahmood, 2014. Aligning manufacturing strategy to export performance of manufacturing small and medium enterprises in Malaysia. Procedia-Social and Behavioral Sciences, 130: 85-95. https://doi.org/10.1016/j.sbspro.2014.04.011

31. Singh, R., 2018. Perspectives on india-bangladesh water dispute: The farakka barrage. Asian Themes in Social Sciences Research, 1(1): 14-20.https://doi.org/10.33094/journal.139.2018.11.14.20

32. Sousa, C.M. and J. Lengler, 2009. Psychic distance, marketing strategy and performance in export ventures of Brazilian firms. Journal of Marketing Management, 25(5-6): 591-610. https://doi.org/10.1362/026725709X461876

33. Sousa, C.M., F.J. Martínez-López and F. Coelho, 2008. The determinants of export performance: A review of the research in the literature between 1998 and 2005. International Journal of Management Reviews, 10(4): 343-374. https://doi.org/10.1111/j.1468-2370.2008.00232.x

34. Stoian, M.C., A. Rialp and J. Rialp, 2011. Export performance under the microscope: A glance through Spanish lenses. International Business Review, 20(2): 117-135.https://doi.org/10.1016/j.ibusrev.2010.07.002

35. Supian, K. and N. Ab, 2018. The role of supplier, top management and government in halal practices integrity of malaysian food business. International Journal of Asian Social Science, 8(8): 549-559.

https://doi.org/10.18488/journal.1.2018.88.549.559

36. Suy, R., L. Chhay and C. Choun, 2018. Protection and management policy on angkor wat temple in cambodia: An overview. Asian Themes in Social Sciences Research, 1(1): 10-13. https://doi.org/10.33094/journal.139.2018.11.10.13

37. Tan, Q. and C.M. Sousa, 2015. Leveraging marketing capabilities into competitive advantage and export performance. International Marketing Review, 32(1): 78-102.https://doi.org/10.1108/IMR-12-2013-0279 